\title{
Sustainable Development of Rural Household Energy in Northern China
}

\author{
Lili Ma (Corresponding author) \\ Gansu Forestry Department \\ No. 1 Qin'an Road, Chengguan District, Lanzhou City, Gansu Province, China \\ Tel: 86-139-1930-6226_E-mail: axiyan417@yahoo.cn
}

Received: August 5, 2011

Accepted: August 18, 2011

doi:10.5539/jsd.v4n5p115

\begin{abstract}
In the rural areas of northern China, the percentage of traditional energy in total energy consumption remains at a high level while the proportion of high-efficient energy and renewable energy is still low. Improving energy efficiency and utilization of renewable energy contributes to improving the sustainable development of rural household energy. Based on descriptive research, relational research and case study etc, this document aims to develop a guide of sustainable practice for rural household energy in northern China. It will be considered for increasing energy efficiency and using renewable energy. Also, it will evaluate the advantages of sustainable development of rural household energy from economic, social and environmental aspects and barriers to implementation of sustainable energy based on three factors: finance, policy and technique. Finally, conclusions and recommendations for sustainable strategies will be proposed to improve rural household energy practice.
\end{abstract}

Keywords: Household energy consumption, Sustainable practice, Energy efficiency, Technical innovation, Renewable energy

\section{Introduction}

Energy indirectly plays a significant role in eradicating poverty, raising living standards and developing economy. Energy deficiency causes more concern among researchers, especially in many developing countries; energy scarcity is a bottleneck restriction which impedes the development of social economy. Specifically, household energy consumption is an important part of peasants' daily life. In the rural areas of northern China, household energy depends on coal and traditional biomass energy such as straw and firewood, which has low efficiency, adversely environmental effects and results in health issue of peasants. The proportion of them in total energy consumption remains at a high level. Comparatively, the percentage of high-efficient energy and renewable energy is still low. In this situation, improving energy efficiency should be considered, additionally, the use of renewable energy such as sustainable biomass energy is increasingly encouraged.

Based on many research methods such as descriptive research, relational research and case study etc, this document aims to develop a guide of sustainable practice for rural household energy in northern China. This document will consider energy efficiency and using renewable energy, followed by an evaluation of the advantages of sustainable development of rural household energy from economic, social and environmental aspects and barriers to implementation of sustainable energy based on three factors: finance, policy and technique. Finally, conclusions and recommendations for sustainable strategies will be proposed to improve rural household energy practice in decreasing emission of green house gas, lowering operating and maintaining cost and ameliorating indoor and outdoor environmental quality.

\section{Current situation}

\subsection{Description of rural areas in northern China}

It is important to understand the current situation of region and population in northern China because it is the basis of this research. To simplify this research, according to Zhou et al (2008), northern China can be divided into northeast, north, and northwest region. They are also considered as province-level administration areas and consist of 14 provinces, including Heilongjiang, Jilin, Liaoning, Beijing, Tianjin, Hebe, Inner Mongolia, Shanxi, Shandong, Ningxia, Shaanxi, Gansu, Qinghai, and Xinjiang (Fig. 1) (Zhou et al 2008). These regions cover 57\% of the land territory of China and the rural population in them was 293 million in 2005, which occupied 30.89\% of the total population. Besides, a large proportion of the population lived below the poverty and the annual net per capita farm income was 3280 RMB (Chinese Yuan), which is 180 RMB less than that of southern China in 
2005 (Zhou et al 2008).

It is also crucial to analyse actuality of natural environment in northern China for this study because it is closely related to energy consumption of rural household. Although per capita land resources are relatively adequate in northern China, the land infertility is a severe issue and a plenty of land is in arid, semiarid or desert regions (Zhou et al 2008). Moreover, environment in northern China is vulnerable due to serious soil erosion, soil desertification, shortages of agricultural water resources and lowering of groundwater levels. Based on this kind of natural environment, agricultural productivity is comparatively low and production of biomass per unit area is lower than that of southern China (Zhou et al 2008).

\subsection{Description of rural household energy consumption situation}

In rural household of northern China, energy usually is used for cooking, lighting, heating, refrigeration, amusement, transportation and others (Deng 2001). According to Zhou et al "Energy sources include not only commercial and traditional renewable energy sources, but also renewable energy sources produced using modern technology" (Zhou et al p2030 2008).

According to statistical yearbook of China and Zhou et al (2008), Table 1 indicates the evolution of the rural household energy consumption structure in northern China from 1996 to 2005. The percentage of traditional biomass energy consumption in total energy consumption declined from $56.0 \%$ in 1996 to $47.2 \%$ in 2005 , while that of commercial energy consumption increased from 43.8 to $52.5 \%$. The quantity of traditional biomass energy consumption has increased from 67.8 million ton of standard coal equivalent (Mtce) in 1996 to 85.5 Mtce in 2005 due to an increasing population and growing energy demand. Compared with traditional biomass energy, commercial energy sources such as coal, oil products and liquefied petroleum gases (LPG) showed large increment during the period of 1996-2005(Zhou et al 2008).

In addition, it is considered that the area used to obtain renewable energy has enlarged quickly in northern China from 1996 to 2005 . For instance, the area where solar energy was generated increased from $9.73 \times 10^{6} \mathrm{~m}^{2}$ in 1996 to $57.40 \times 10^{6} \mathrm{~m}^{2}$ in 2005 . Moreover, energy-saving stoves and kangs, traditional brick sleeping platforms have developed quickly in recent years (Table 2) (Zhou et al 2008).

As can be illustrated from Fig.2 (Zhou et al 2008), due to the quest for convenience, comfort and sanitary conditions in daily life, the energy consumption structure has been steadily improved.

\section{Guide for sustainable practice for rural household energy}

\subsection{Improving energy efficiency}

According to statistics, in rural areas of northern China, the number of households using energy-saving stoves increased to 57.83 million in 2005 , however, the average thermal efficiency of cooking stoves is relatively low (Zhou et al 2008). Moreover, with increasing concerns for indoor environment quality, health issue and the emission of greenhouse gases, improving the sustainability of household energy use is more crucial for residents in rural areas of northern China. Under the circumstances, more integrated and systemic approaches for reformative cook stove programs need to be improved rather than projects restricted with stove construction or sales.

\subsubsection{Technology innovation}

1) General guide

Setting up a progress of continuous technology innovation is one of the main program goals and contributes to laying the foundation for integrated approaches. Firstly, the laboratory of cook stove ought to be set up. It is used in research and development of cook stove with high efficiency and test of cook stove designs and materials. Secondly, holistic valuation system for thermodynamic performance of cook stove should be established. It would contribute to detection of emission profile of major pollutants generated from cook stove and then ameliorating the indoor air quality of households. In addition, the valuation system can be utilized as a reference or standard to test other cook stove models that currently being disseminated in rural areas of China.

2) Case study

Case clarification

According to Masera et al, there is a kind of new massive multi-pot wood-burning cook stove being developed in Mexico, which aims to improve indoor environmental quality, residents' health and economic condition of group with low income. The cook stove has the following improvements:

a) Optimization design of the combustion chamber and tunnels 
b) "Custom-designed parts for durability, including a metal chimney support and a ceramic stove entrance (see Fig.3 below)" (Masera et al p29 2000).

c) Construction time reduction and inner dimensions standardization (Masera et al 2000).

Case analysis

The new concept of massive wood-burning cook stove can be disseminated in rural areas of northern China because it poses the following merits:

a) Minimizing the consumption of natural resources and tending to use the materials with low embodied energy. This is because the cook stove is made of a mixture of sand, mud and a small amount of cement, which are available locally.

b) Meliorating indoor air quality of households and then ameliorating indoor environmental quality for peasants, especially for women and children in rural areas. This is because the metal flat pans of the cook stove are tightly adjusted to the furnaces to prevent smoke leakage and therefore avoid leaking of the smoke polluting indoor environmental quality.

c) Reducing fuel consumption and improve energy efficiency since tunnels included in models conduct the combustion gases to secondary chambers which are used for low power cooking tasks, such as keeping food warm or heating water. Consequently, the advanced cook stove is in favor of saving energy and maximizing energy efficiency.

\subsubsection{Cook stove dissemination}

Technology innovation is relatively important for improving energy efficiency of rural household energy in northern China. The dissemination of advanced cook stove is coequally significant as well as playing an active role in sustainable development of rural areas. In order to achieve the improved cooking stove dissemination of rural areas in northern China, some measures should be taken as follows:

1) Increasing farmers' awareness of environmental protection

In the cook stove dissemination process, cook stove users is the main source-for the basis of the process and is beneficial for setting up sustainable business operation at the rural regional level. In rural areas of northern China, traditional resources are usually used during a long period partly due to low educational level of farmers and weak awareness of environment protection. To reduce over-exploitation of biomass resources and optimizing the structure of energy consumption, it is crucial to rise farmers' awareness of environmental protection and acceptability of advanced cook stove. Specifically, it is necessary to make peasants especially women more aware the detriment derived from direct combustion of straw, firewood and coal for cooking and heating, additionally, to enable them to focus on indoor environmental quality and health issue. These objects can be achieved by means of operating training workshops (Masera et al 2000). In specific, women in rural areas would involve a general presentation of the project in an assembly of the village and understand the main features of the advanced cook stove and how to use it.

\section{2) Increasing famers' income and financial incentive implementation}

Except for increasing peasants' awareness of environmental protection, financial incentive is equally essential for a fast adoption of improved cook stove. This is because a large number of peasants are still relatively poor and have low payment ability for household energy consumption. Therefore, increasing famers' income is necessary for encouraging them to buy improved cook stove and then improve energy efficiency. Besides, financial incentive implementation is another viable way to accelerate advanced cooking stove dissemination. According to Masera et al, there are two types of incentives: "a $20 \%$ discount on stove costs for the first 50 stoves built within each village; and (2) a 'payment in installments' type of micro-finance, that is set up --where needed -- to help users to overcome up-front costs (stoves are paid for in 3 installments)" (Masera et al 2000 p31).

\subsection{Using renewable energy}

In order to maximize the sustainable practice for rural household energy in northern China, the use of renewable energy should be increased and it also plays an increasingly important role in improving energy efficiency. Based on geographical condition of northern China, the region has abundant renewable energy resources and vast tracts of unproductive agricultural land which are suited to energy plant construction (Zeng et al 2005)

Biomass is the significant energy source in China, particularly in rural areas. According to Zeng et al, "The major sources of traditional biomass are crop residues and firewood and their share in energy supply is approximately 46\%" (Zeng et al. 2005 pp 980). However, over-depending on firewood and agricultural residues 
brings detrimental effect on indoor environmental quality and associates adverse health impacts. Therefore, modernized biomass technology can have a profound influence on sustainable development of rural household energy because sustainable use of biomass causes no net increase in $\mathrm{CO}_{2}$ emission.

\subsubsection{Biomass technology introduction}

There are three biomass energy technologies prevalently being used in rural areas of northern China, which are anaerobic digestion, straw gasification and straw briquette. Choosing one of them to give introduction below:

According to Zeng et al, anaerobic digestion (or biogas technology) depends on biogas which can be generated by mixing with straw, human waste, animal dung and organic wastes in the condition of anaerobic environment and then produce energy used in generating electricity and heat (see Fig 4 below). It is a bioconversion technology widely adopted in China. Zeng et al reported that "the main composition of biogas is $\mathrm{CH}_{4}$, accounting for $60-70 \%$, and its heat value is about $2.5 \times 104 \mathrm{~kJ} / \mathrm{m} 3$, equivalent to $1 \mathrm{~kg}$ raw coal or $0.76 \mathrm{~kg}$ standard coal"'(Zeng et al 2005 pp 970). Moreover, biogas is a kind of eco-agricultural technology which is applied by integrating the use of residues from livestock and straw. Because of high gas productive, low construction cost, simple maintenance, long operational life and easy dissemination, the technology can improve indoor and outdoor environment of household and ameliorating living condition of peasants. Except for as a solution to household fuel, biogas fluid can be used to grow fruit trees, vegetables and grain as well as succulence to breed farms (Zeng et al 2005). Thus, as a kind of renewable energy, biogas is beneficial for improving sustainable practice for rural household energy in northern China.

\subsubsection{Some aspects of research and development}

As a big agricultural country, China has a large quantity of straw across the country (Tao, 2001). However, China is confronted with the challenge of how to use this resource to their advantage and develop, manage the sufficient, affordable and reliable energy in a sustainable way. Besides, it is also significant to consider that whether using straw in biomass energy can comply with a sustainable manner for fuel's social and economic development and environmental amelioration. Some aspects of research and development in rural areas of China currently are as follows:

1) In order to reduce the cutting quantity of firewood and the use of fossil energy resources, especially coal, the combustion efficiency of advanced stove and the aerogenesis efficiency of straw anaerobic digestion should be enhanced. Therefore, development of comprehensive biogas eco-agricultural technology and popularization of improved stove are important aspects focused on to satisfy the needs of rural domestic energy (Tao, 2001).

2) Based on the real situation and technology, straw gasification systems for central gas supply should be disseminated in rich areas (see Fig.5). Specifically, the relative technology of high calorific values (CV) of straw gasification should be researched as well as straw direct combustion technology. Furthermore, the efficiency and the range of its applications should be improved by means of developing the straw direct combustion boiler and relative equipments for large-scale utilization of straw on generating electricity and supplying heat. (Zeng et al)

3) International cooperation and intercommunion are relatively vital since it can accelerate the steps of advanced technology of straw utilization in China, especially in rural areas (Wang \& Fen 2002). Thus, it may contribute to establishing the renewable energy utilization and development structure for household energy in rural areas.

\section{Judgments of sustainable development of rural household energy}

\subsection{Advantages}

The dissemination of sustainable energy in rural areas of China has led to a number of benefits. Sustainable energy contributes to ameliorating air quality, reducing pollution to water, soil and vegetation. Firstly, sustainable energy, including renewable energy and sustainable managed biomass, can mitigate the environmental impacts of energy use. The following is a case in point: In rural areas of northern China, there is adequate solar energy source; therefore peasants get the thermal power from the sun to heat water which can be used for cooking, bathing and generating electricity (Wang \& Fen 2002). Besides, using sustainable energy can avoid some issues effectively such as deforestation, exacerbation of soil erosion and loss of organic matter in soil. Wang and Fen(2002) report that liquid fuels like ethanol is produced simply from sugar producing agricultural crops such as sweet sorghum, sugarcane etc, that have sustainable competitive advantages because of sustainability of resources and environmental-friendly products (Wang \& Fen 2002).

As for economic effectiveness for society, integrated utilization of sustainable energy does not only satisfy the household energy needs, but it also increases the income of farmers. Because the geographical access for potential consumers to energy grid is an issue in rural areas, especially in some remote regions, it hinders 
peasants to get transmission and distribution of energy. Sustainable energy could address this issue effectively. This is illustrated by following examples: It is estimated that $500 \mathrm{~m}^{3}$ of biogas can be annually produced by each biogas plant, which is equal to saving 2.5-3 tons of firewood and $3000 \mathrm{~kg}$ of organic fertilizer ( $\mathrm{Li}$ et al as cited Bhatt 2004). Additionally, Li et al (2004) report that one biogas plant (for one household) could cause an annual reduction in expense of 300-500 RMB in purchasing firewood or coal for energy, and increase income by 100 RMB from animal husbandry ( $\mathrm{Li}$ et al 2004).

Sustainable energy is also the best interests of peasants from social aspect. The first argument for sustainable energy is it can improve living standards of farmers. According to Byrne et al (1998), grid electricity is inaccessible for many remote rural areas of China, hence giving rise to restriction of other technical and social infrastructure's quality (Byrne et al 1998). While depending on sustainable energy, farmers use solar thermal systems to heat water, dry agricultural products etc, and most importantly, they are exposed to television, refrigerator and some infrastructure as same as urban residents. Then, sustainable energy can promote the melioration of sanitary condition, and therefore minimizing the adverse effects of traditional biomass energy on health. For example, Jin et al $(2007$, p. 5) demonstrate that "in western China, the novel advanced clean energy with low pollution would reduce pollutant emissions by $10-40 \%$ in comparison to the traditional technology" (Jin et al 2007). It indicates sustainable energy is an effective way to reduce exposure to hazardous pollutants and meliorate health condition of people, especially, women and children in rural areas.

\subsection{Barriers}

Financial, political and technical barriers have obstructed the rapid sustainable development of rural household energy. The main barrier is economy. The majority of population in rural areas cannot afford high price of electricity generated from sustainable energy due to the relatively high initial investment in plant and peasants' low purchasing power. Liu et al report that "the price of a degree electricity is $0.5 \mathrm{RMB}$ at present, and the price of PV generate electricity is more than 5 RMB" (2009:309). Beside this, the market of sustainable energy application in China is small and unsecured currently; hence potential producers will not invest capital in it. For instance, the total yield of PV in 2008 is about $2000 \mathrm{MW}$, but the domestic PV production has a very little yield, and the annual total is less than 10MW over the last 10 years (Liu et al 2009). The essential reason is the costly price of PV production, which also exceeds the farmers' purchasing ability. In brief, initial investment of sustainable energy cannot be founded by impoverished group.

Another constraint on dissemination of sustainable energy in rural areas of China is different policies between central government and local government. Although the macroscopic and hortative policy has been established by central government, the local government is difficult to implement because they hesitant whether developing sustainable energy can foster the enhancement of regional economies. Specifically, some northern and western provinces in China possess adequate fossil resources while the deficiency of fossil resources is a major issue in east and south of China (Liu et al 2009). Accordingly, the impetus of using sustainable energy is smaller in northern and western rural areas. Furthermore, owing to necessary huge investment in sustainable energy, local governments are usually suffering from the financial pressure, and thereby rejecting the policies and regulations of the central government (Liu et al 2009).

Additionally, local governments and experts do not focus on the technology of sustainable energy in rural areas of China. For instance, the university and graduate school presently have not placed emphasis on the technology of PV and the technical investment in exploration of sustainable energy is insufficient in impoverished regions (Wang \& Chen 2009). Also, there is no course referring to the interrelated technology of renewable energy in Chinese university and no correlative student graduate from the renewable region. Moreover, people who have ability of renewable region are not cultivated in corporation, and therefore they cannot devote to development of sustainable energy (Liu et al 2009). Technology transfer is another obstacle. For example, "As mentioned earlier, HFC-23 and $\mathrm{N}_{2} \mathrm{O}$ CDM projects can receive the highest CERs, so the incentive from carbon market is enough to drive not only transfer equipment, but also involve significant amounts of knowledge transfer for it" (Wang \& Chen p1995 2009).

\section{Conclusion}

In conclusion, dissemination of sustainable energy is obstructed by financial, political and technical barriers. Despite that, the utilisation of sustainable energy should be highly encouraged in rural areas since it has provided enormous benefits, including ameliorating adverse impacts on environment, boosting economic development and improving peasants' living standards. Therefore, in order to minimize the obstacles and assist the development of sustainable energy in rural areas, it is necessary to first improve energy efficiency. Specifically, local governments need to invest in researching and distributing advanced energy-saving facilities. Also, authorities 
need to apply research and development funding for sustainable energy technologies especially granting for low-income household, expert advice and training. Indeed, widespread of public awareness, acceptability and participation are also essential for popularizing sustainable energy. Accordingly, the most critical factor is raising peasants' awareness of using this form of energy. Overall, if countermeasures above can be performed effectively, the sustainable energy may contribute to sustainable development of rural areas in China and then direct the whole society towards the environmental, economic social benefits.

\section{References}

Byrne, J., Shen, B., \& Wallace, W. (1998). The economics of sustainable energy for rural development: A study of renewable energy in China. Energy Policy, 26(1), 45-54, doi: doi:10.1016/S0301-4215(97)00099-2, http://dx.doi.org/10.1016/S0301-4215(97)00099-2

Deng, K.Y. (2001). Theory and practice of China integrated rural energy development. (2rd ed.). China: Beijing: China's Environment Science Press.

Jin, H.G., Xu, G., Han, W., Gao, L., \& Li, Z. (2007). Sustainable development of energy systems for western China. Energy, 35(11), 4313-4318, doi:10.1016/j.energy.2009.04.027, http://dx.doi.org/10.1016/j.energy.2009.04.027

Li, Z.M., Tang, R.S., Xia, C.F., Luo, H.L., \& Zhong, H. (2004). Towards green rural energy in Yunnan, China. Renewable Energy, 30(2), 99-108, doi:10.1016/j.renene.2004.05.011, http://dx.doi.org/doi:10.1016/j.renene.2004.05.011

Liu,L.Q., Wang, Z.X., Zhang, H.Q., \& Xue, Y.C. (2009). Solar energy development in China-A review. Renewable and Sustainable Energy Reviews, 14(1), 301-311, doi:10.1016/j.rser.2009.08.005, http://dx.doi.org/ 10.1016/j.rser.2009.08.005

Masera, O.R., Saatkamp, B.D., \& Kammen, D.M. (2000). From linear fuel switching to multiple cooking strategies: a critique and alternative to the energy ladder model for rural households. World Development, 28(12), 2083-2103, doi:10.1016/S0305-750X(00)00076-0, http://dx.doi.org/10.1016/S0305-750X(00)00076-0

Rural energy statistical yearbook of China. Ministry of Agriculture of the Peoples Republic of China. Beijing: Chinese Agriculture Press, 1996-2005. Available: http://www.agri.gov.cn/index2.htm

Statistical yearbook of China. Beijing: China Statistical Publishing House, 1996-2005. Available: http://www.stats.gov.cn/tjsj/ndsj/2005/indexeh.htm

Wang, Q., \& Chen, Y. (2010), Barriers and opportunities of using the clean development mechanism to advance renewable energy development in China. Renewable and Sustainable Energy Reviews, 14(7), 1989-1998, doi:10.1016/j.rser.2010.03.023, http://dx.doi.org/doi:10.1016/j.rser.2010.03.023

Wang, X.H., \& Fen, Z.M. (2002). Sustainable development of rural energy and its appraising system in China. Renewable and Sustainable Energy Reviews, 6(4), 395-404, doi:10.1016/S1364-0321(02)00007-2, http://dx.doi.org/10.1016/S1364-0321(02)00007-2

Yin, C.T. (2001). Using Integrated Household Biogas Technology for Protecting Forest and Helping Poor Community in Baima Snow Mt. Nature Reserve, Yunnan Province, South-North Institute for Sustainable Development, Zhongshan Park, Beijing 100031, China. Available: www.energia.org/fileadmin/files/media/EN082002_chuntao.pdf

Zeng, X.Y., Ma, Y.T., \& Ma, L.R. (2005). Utilization of straw in biomass energy in China. Renewable and Sustainable Energy Reviews, 11(5), 976-987, doi:10.1016/j.rser.2005.10.003, http://dx.doi.org/ 10.1016/j.rser.2005.10.003

Zhou, Z.R., Wu, W.L., Chen, Q.S., \& Chen, F. (2007). Study on sustainable development of rural household energy in northern China. Renewable and Sustainable Energy Reviews, 12(8), pp. 2237-2239, doi:10.1016/j.rser.2007.03.007, http://dx.doi.org/10.1016/j.rser.2007.03.007 
Table 1. Rural household energy consumption (_1 $10^{4}$ tce) in northern China (1996-2005)

Rural household energy consumption $\left(\times 10^{4}\right.$ tce) in northern China (1996-2005)

\begin{tabular}{llllllllllrr}
\hline Year & Total & Straw & Firewood & Coal & Electricity & $\begin{array}{l}\text { Oil } \\
\text { products }\end{array}$ & Biogas & LPG & $\begin{array}{l}\text { Natural } \\
\text { gas }\end{array}$ & Coal gas \\
\hline 1996 & $12,110.25$ & 5107.15 & 1676.82 & 4172.88 & 948.45 & 118.23 & 18.53 & 62.57 & 1.67 & 3.95 \\
1997 & - & - & - & - & - & - & - & - & - & - \\
1998 & $15,202.57$ & 5563.17 & 1965.81 & 5964.37 & 1239.45 & 230.91 & 17.67 & 198.12 & 16.20 & 6.85 \\
1999 & $13,537.94$ & 5599.27 & 1854.07 & 4691.03 & 1037.04 & 239.80 & 18.14 & 88.24 & 3.49 & 6.86 \\
2000 & $14,186.37$ & 5509.74 & 1993.04 & 5173.40 & 1075.06 & 291.29 & 20.32 & 110.43 & 6.34 & 6.76 \\
2001 & $15,542.04$ & 5556.58 & 2185.42 & 6275.68 & 1095.74 & 316.65 & 21.73 & 74.06 & 8.63 & 7.54 \\
2002 & $16,410.74$ & 5800.58 & 2398.68 & 6732.68 & 1008.11 & 309.65 & 24.7 & 116.41 & 14.53 & 5.37 \\
2003 & $17,365.56$ & 6227.61 & 2518.78 & 6940.75 & 1098.99 & 382.47 & 36.7 & 146.68 & 8.39 & 5.16 \\
2004 & $17,502.03$ & 6089.77 & 2613.30 & 7068.10 & 1126.47 & 413.92 & 45.96 & 131.22 & 8.43 & 4.82 \\
2005 & $18,152.12$ & 5975.83 & 2574.33 & 7594.38 & 1172.01 & 552.34 & 66.28 & 160.07 & 10.98 & 18.90 \\
\hline
\end{tabular}

Note: (1) Calculated according to rural energy statistical yearbook of China [5], 1996-2005; (2) vacant of some data of 1997.

Table 2. Development of the major modern renewable energy sources and energy-saving measures in rural areas of northern China

Development of the major modem renewable energy sources and energy-saving measures in rural areas of northern China

\begin{tabular}{|c|c|c|c|c|c|c|c|c|c|c|}
\hline Year & 1996 & 1997 & 1998 & 1999 & 2000 & 2001 & 2002 & 2003 & 2004 & 2005 \\
\hline Solar energy $\left(10^{4} \mathrm{~m}^{2}\right)$ & 973 & $-{ }^{2}$ & 988 & 1000.82 & 1313.5 & 1338.75 & 1917.16 & 3185.91 & 4995.02 & 5739.53 \\
\hline $\begin{array}{l}\text { Wind power } \\
\left(10^{4} \mathrm{kWh}\right)\end{array}$ & $-^{a}$ & $-^{a}$ & $-{ }^{a}$ & 2118.54 & 1909.28 & 2633.32 & 3099.92 & 3101.44 & 2993.23 & 3131.67 \\
\hline $\begin{array}{l}\text { Amounts of straw } \\
\text { gasification stations }\end{array}$ & $-^{a}$ & $-^{a}$ & 158 & 200 & 284 & 289 & 313 & 337 & 341 & 367 \\
\hline $\begin{array}{l}\text { Energy-saving stoves }{ }^{b} \\
\left(10^{4} \text { users) }\right.\end{array}$ & 5127.29 & 5308.29 & 5441.78 & 5599.81 & 5640.73 & 5691.21 & 5707.23 & 5738.59 & 5758.29 & 5782.97 \\
\hline $\begin{array}{l}\text { Energy-saving kangs }{ }^{b} \\
\left(10^{4} \text { users }\right)\end{array}$ & 1569.48 & 1607.63 & 1677.59 & 1754.81 & 1813.45 & 1861.44 & 1892.35 & 1901.05 & 1923.09 & 1942.44 \\
\hline
\end{tabular}

${ }^{2}$ Statistics on the use of solar energy in 1997, straw gasification stations during 1996-1997 and wind power during 1996-1998 were scarce.

${ }^{\mathrm{b}}$ Energy-saving stoves and energy-saving kangs include modern and older forms. 


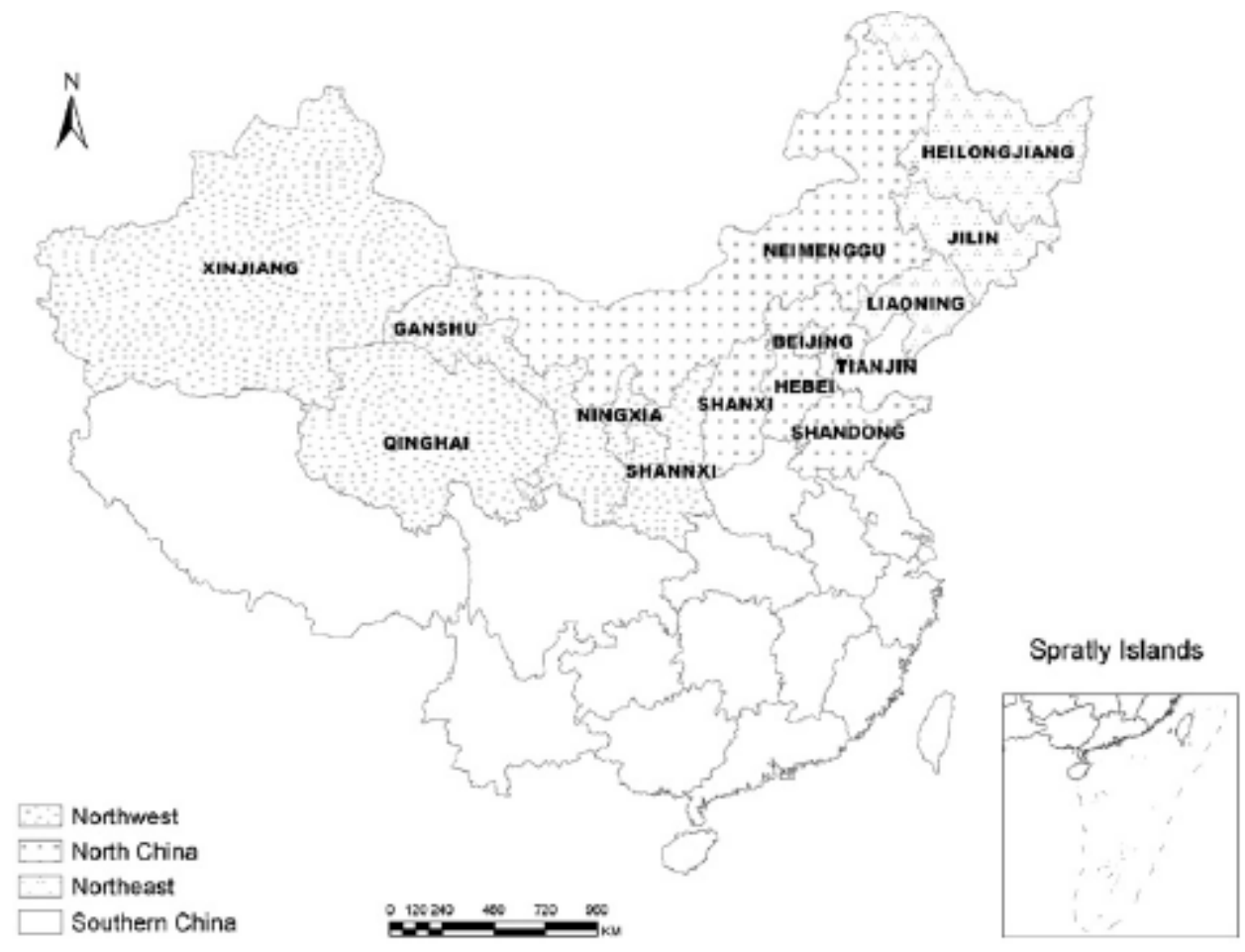

Figure 1. Provinces comprised the main northern regions of China
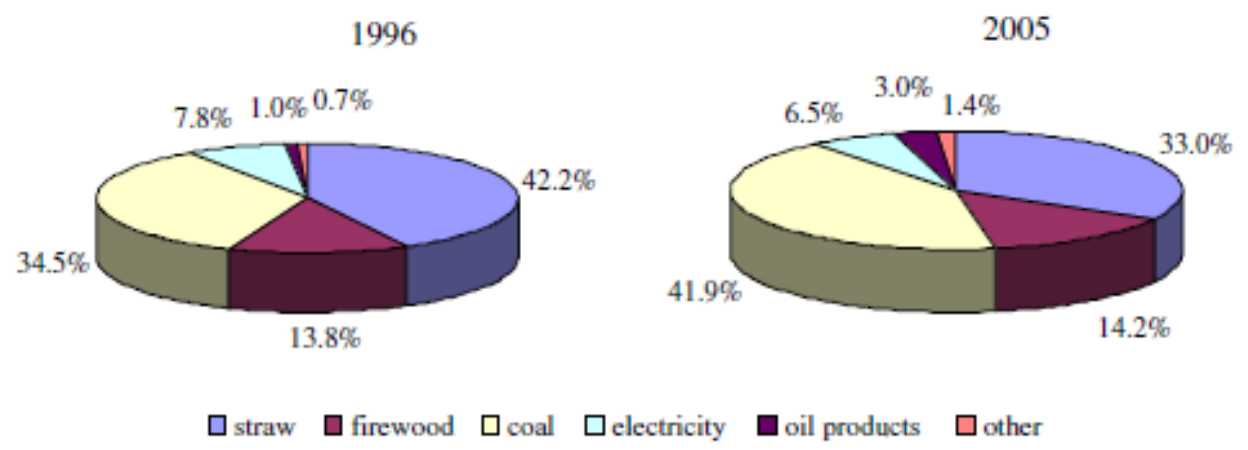

Figure 2. Household energy consumption structure in rural areas of northern China 


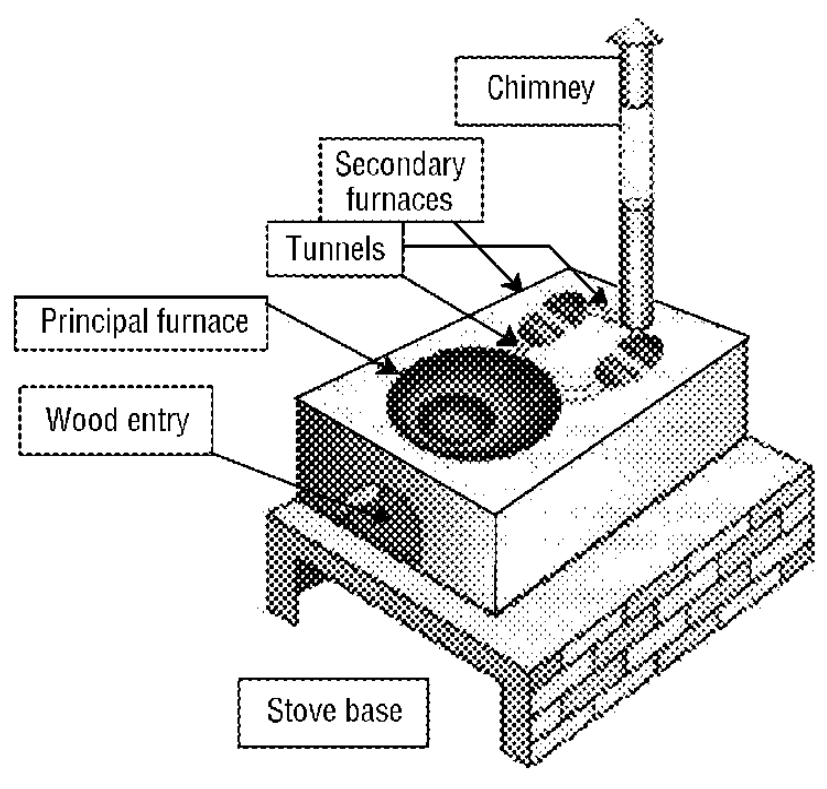

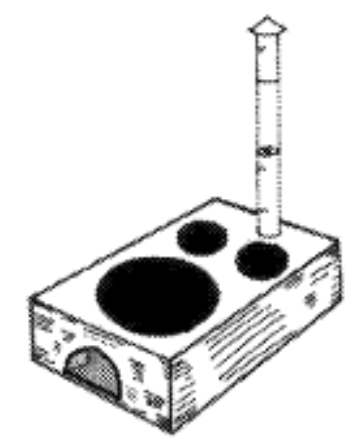

Single-entry Patsari

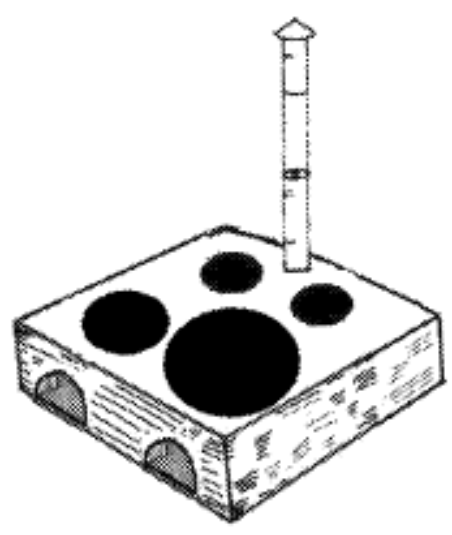

Double-entry Patsari

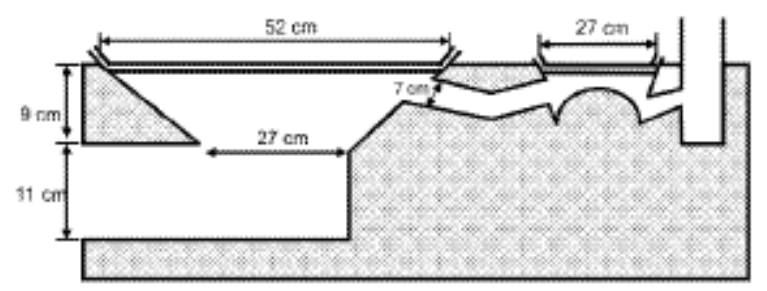

Cross-sectional view of primary comal

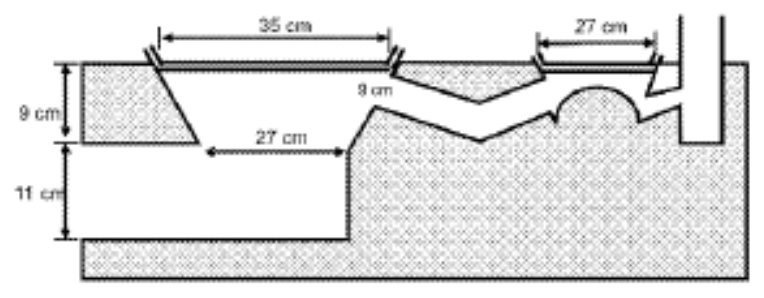

Cross-sectional view of secondary comal (for double-entry Patsari only)

Figure 3. Top view and cross-sectional view of the two Patsari cookstove models 


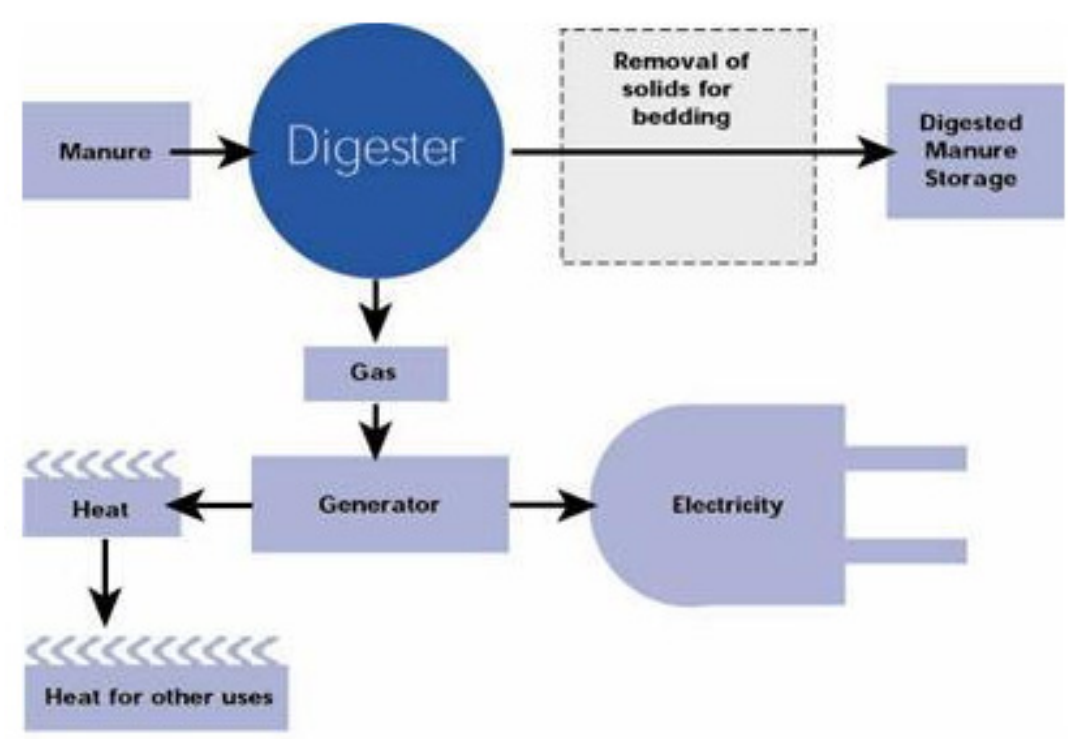

Figure 4. Principle of anaerobic digestion

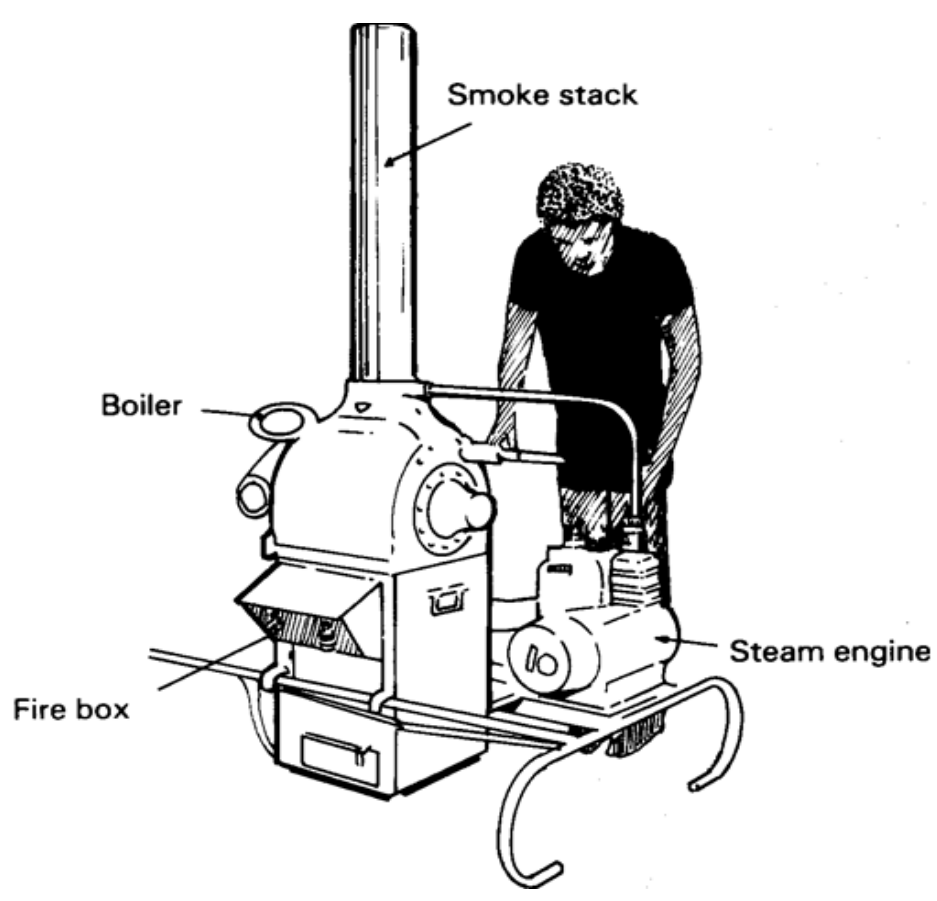

Figure 5. Sample of straw gasification systems for central gas 